MASLINKIEWICZ, A.; FREITAS, D. R. J. Micotoxinas: o que são e quais suas conse quências para o homem?. SB RURAL, Chapecó, 17 Mai. 2012. Caderno Rural, p. 1 4. Disponível em: <http://www.ceo.udesc.br/arquivos/id submenu/285/caderno udesc 087.pdf $>$. Acesso em: 22 Set. de 2014

MENEGHELLO, E. R.; JORGE, J. R.M.; OLIVEIRA, A.V. Identificação e Pesquisa de espécies de fungos Aspergillus nige e Aspergillus carbonarius encontradas em frutas secas vendidas no comércio de Maringá-PR. In: VI MOSTRA INTERNA DE TRABALHOS DE INICIAÇÃO CIENTÍFICA, 2012, Maringá-PR. Identificação e Pesquisa de espécies de fungo.,6. Anais Eletrônicos.. aspergillus. Níger e Aspergillus Carbonarius encontrados em frutassecas vendidas no comércio de Maringá PR. Maringá PR6, Maringá: CESUMAR, 2012 p.1 9. Disponível em: $<$ http://www.cesumar.br/prppge/pesquisa/ mostras/vi mostra/jessica raynne moura jorge 2.pdf $>$ Acesso em: 5 Set. 2014.

AS MICOTOXINAS. Revista Food Ingredients Brasil. N. 7, p32- 40, 2009. Disponível em: $<$ http:// www.revista-fi.com/materias/90.pdf $>$ Acesso em 24 Jun. 2014.

MOREAU, R. L. M.; SIQUEIRA, M. E. P. B. Toxicologia Análitica: Ciências Farmacêuticas.1 ed. Rio de Janeiro: Guanabara Koogan, 2001.p.199.

OLIVEIRA, J. N.; OLIVEIRA, A. V.; MENEGHELLO, E. R. Análise Molecular de espécies de Aspergillus contaminantes de uvas vendidas no comércio de Maringá PR. Iniciação Científica CESUMAR. v. 15, n. 2, p. 157-163, Jul/ Dez. 2013.

PEREYRA, C. M.; CAVAGLIERI, L. R.; CHIACCHIERA, S. M.; DALCERO, A M. Fungi and Mycotoxins in Feed Intended for Sows at Different Reproductive Stages in Argentina. Veterinary Medicine International, v. 2010, p.1-7, Apr. 2010.

PERRONE, G.; SUSCA, A.; COZZI, G.; EHRLICH, K.; VARGA, J.; FRISVAD, J. J. C.;MEIJER, M.; NOONIM, P.; MAHAKARNCHANAKUL,W.; SAMSON, R. A. Biodiversity of Aspergillus species in some important agricultural products. Studies in Mycology, v.59, n.09, p.53-66, 2007.

SANTOS, C. C. M.; LOPES, M. R. V; KOSSEKI, S. Y. Ocorrência de aflatoxinas em amendoim e produtos de amendoim comercializados na região de São José do Rio Preto/SP. Revista Instituto Adolfo Lutz, v.60, n.2, p. 153-157, 2001

SIDRIM, J. J. C.; MOREIRA, J. L. B Fundamentos clínicos e laboratoriais da micologia médica. 1 ed. Rio de Janeiro: Guanabara Koogan, 1991. p. 1-274.

TANIWAKI, M. H.; MARTINS, C. P.; IAMANAKA, B. T.; LEITE, R. S. S. F.; VICENTE, E.; OKAZAKI, M.M. Aspergillus niger e Aspergillus carbonarius produtores de ocratoxina a em alimentos: ocorrência, significado e fatores que afetam a sua presença. REVNET DTA Revista Eletrônica de Epidemiologia das Doenças Transmitidas por Alimentos. v. $4, \mathrm{n} .1$ 2004. Disponível em: <ftp://ftp.cve.saude.sp.gov. $\mathrm{br} /$ doc_tec/hidrica/revp04_vol4n1.pdf $>$ Acesso em: 19 Set. 2014

WELKE, J. E.; HOELTZ, M.; NOLL, I. B. Aspectos relacionados à presença de fungos toxigênicos em uvas e ocratoxina A em vinhos. Ciência Rural, v.39, n.8, p.2567-2575, Nov. 2009.

ZAITZ, C.; RUIZ, L. R. B.; SOUZA, V. M. S. Atlas de Micologia Médica: Diagnóstico Laboratorial. 2 ed. Rio de Janeiro: MEDSI, 2004. p.2-169.

\section{PESQUISA DE BIOINDICADORES EM \\ SALSICHAS VENDIDAS A GRANEL EM SUPERMERCADOS DO NOROESTE PAULISTA}

Bruna Tavares Bruno ${ }^{1}$

Livia Alegria dos Santos

Cátia Rezende

\section{RESUMO}

A pesquisa de Escherichia coli e Salmonella spp. nos alimentos é um importante bioindicador higiênicosanitário, indicando contaminação fecal. A salsicha é um alimento muito consumido e de fácil preparo, entretanto, se manipulada de maneira inadequada, pode se tornar uma excelente fonte de contaminação e proliferação de micro-organismos. Para se analisar a presença dessas bactérias, foram coletadas 32 amostras de salsichas em supermercados de pequeno e grande porte. A análise microbiológica quantitativa para Escherichia coli foi realizada em ágar EMB e para Salmonella spp., em ágar SS. Colônias suspeitas foram identificadas por testes bioquímicos. Do total de amostras coletadas, 50\% apresentaram crescimento de Escherichia coli e para Salmonella spp não houve crescimento. Esses dados comprovam a necessidade de uma maior fiscalização higiênico-sanitária nos estabelecimentos comerciais e uma maior atenção da população aos alimentos que estão sendo ingeridos.

Palavras-chave: Bioindicador; Contaminação; Doenças Intestinais. 


\section{Biomarkers research in sausages sold in bulk in supermarkets of the Northwest Region of São Paulo state}

\section{ABSTRACT}

The Escherichia coli research and Salmonella spp. in foods is an important hygienic-sanitary bioindicator, indicating fecal contamination. The sausage has a very easy preparation and consumption, however, if handled improperly, can become an excellent source of contamination and proliferation of micro-organisms. To analyze the presence of these bacteria, 32 samples of sausage were collected in large and small supermarket. The quantitative microbiological analysis for Escherichia coli was made in EMB agar, and for Salmonella, in SS agar. Suspect colonies were identified by biochemical tests. Of the total samples, $50 \%$ showed growth of Escherichia coli and Salmonella spp. presented no growth. These data demonstrate the necessity for a greater hygienic sanitary inspection in commercial establishments and a greater attention of the population to the food which is being ingested.

KEYWORDS: Bioindicator; Contamination; Intestinal Diseases.

\section{INTRODUÇÃO}

Os produtos cárneos de salsicharia são elaborado com massa de carne crua, cozida ou defumada, embutida ou ensacada. As matérias-primas são carnes ou outros tecidos animais comestíveis, de carnes ou outros tecidos animais comestiveis, de
uma ou mais espécies animais (MARTINS, 2006), sendo revestida por envoltório natural, tripas, bexigas ou outras membranas animais, podendo ser obtida artificialmente ou por processo de extrusão (BRASIL, 2000; DUARTE, 2005). Estes produtos apresentam um amplo consumo popular, com tendência a um contínuo crescimento, devido ao seu baixo custo e curto tempo de preparo (FORTUNA, 2005). Além disso, representam uma forma prática e saborosa de ingestão de proteína animal.

Entretanto, os alimentos cárneos, particularmente aqueles que passam por apreciável manuseio, se constituem em excelente meio de cultura devido à elevada porcentagem de umidade, $\mathrm{pH}$ próximo à neutralidade e composição rica em nutrientes; favorecendo a instalação, sobrevivência e multiplicação de grande número de microorganismos capazes de provocar toxinfeccões no homem (KASNOWSKI, 2004).

As doenças bacterianas transmitidas por alimentos são muito prevalentes no Brasil e no mundo, podendo ocorrer sob a forma de surto ou individualmente. A contaminação bacteriana de alimentos representa sério problema de segurança alimentar, sendo responsável por mais de $90 \%$ das ocorrências de Doenças Transmitidas por Alimentos - DTA (PAVIA; BORGES; PANETTA, 2000).

Experimentos tem demonstrado a sobrevivência de patógenos por várias semanas a meses numa variedade de alimentos ácidos incluindo maionese e salsichas. A sobrevivência, nestes alimentos, é prolongada quando estocados a temperatura de refrigeração (FRANCO, 2002).

A qualidade de um alimento pode ser definida através das características microbiológicas, baseada em parâmetros higiênicos e sanitários da matériaprima usada e do processo para obtenção do produto final. Os parâmetros de avaliação sanitária tem relação direta com a presença de micro-organismos potencialmente patogênicos, estabelecidos através da legislação (BRASIL, 2001, BRASIL, 2003).

A carne está exposta à contaminação por 0 desde a sangria até 0 momento do consumc patógenos como Escherichia coli, Salmonella spp e Shigella spp (BOPP et al., 2003, PABST et al., 2003, WINOKUR et al., 2001, ZWEIFEL et al., 2004).

Os micro-organismos patogênicos de maior ocorrência relatados envolvidos em situações de DTAs e de risco para a saúde pública são: Salmonella, Shigella, Escherichia coli, Staphylococcus aureus, Bacillus cereus e Clostridium perfringens (CÂMARA, 2002). Segundo a Instrução Normativa n. ${ }^{\circ} 62$ do Ministério da Agricultura

Pecuária e Abastecimento, as análises que devem ser realizadas para salsichas são: Coliformes a $45^{\circ} \mathrm{C}$ Staphylococcur Staphylococcus coagulase positiv, Salmonella e Clostridium sulfito redutor (Brasil, 2003).

A crescente demanda de produtos industrializados de conveniência, minimamente processados, refrigerados e prontos para o consumo, tem contribuído para que o risco de enfermidades transmitidas por alimentos aumente (Mc CORMICH et al., 2005; SAMUEL et al., 2007).

Vale salientar que a subnotificação dos surtos de origem alimentar pelos serviços de vigilância epidemiológica é uma realidade mundial (ICMSF, 2002). Segundo Forsythe (2002), somente $10 \%$ do no Brasil, devido às falhas no sistema de notificação e de fiscalização.

Dentro deste contexto, objetivou-se avaliar as condições higiênico-sanitárias de salsichas vendidas a granel em supermercados de pequeno e grande porte de uma cidade do Noroeste Paulista através da presença de bioindicadores fecais.

\section{METODOLOGIA}

O estudo foi realizado em diversos supermercados do Noroeste Paulista Foram coletadas 32 amostras de salsichas de diferentes 
marcas e em supermercados de pequeno e grande porte. Os supermercados de pequeno porte foram considerados aqueles de bairros pequenos e com pouco movimento, já os supermercados de grande esentam um grande fluxo de pessoas e situam-se no centro comercial da cidade. No momento da coleta, porções individuais foram acondicionadas em sacos estéreis, lacrados, transportados em temperatura ambiente $\left(22-25^{\circ} \mathrm{C}\right)$ em caixas térmicas para o Laboratório Didático de Análises Clínicas do Centro Universitário de Votuporanga (UNIFEV)

As análises microbiológicas para pesquisa quantitativa de Escherichia coli foram feitas po diluição seriada e cultivo em meio seletivo. $25 \mathrm{~g}$ de salsicha foram homogeneizadas em $225 \mathrm{~mL}$ de água salina peptonada (diuição 10-1). Após 60 segundos de agitação, $1 \mathrm{~mL}$ desta diluição foi aliquotada (diluição 10-2). Este tubo foi agitado com utilização do vórtex, com posterio transferência de $1 \mathrm{~mL}$ para um tubo com $9 \mathrm{~mL}$ do mesmo diluente (10-3). Posteriormente, as diluições seriadas foram cultivadas $(0,1 \mathrm{~mL})$ em placas de Agar EMB (Biolife ${ }^{\circledR}$ ) e incubadas a $35 \pm 1^{\circ} \mathrm{C}$ por 24-48 horas. Colônias foram submetidas à identificação por provas bioquímicas: kit EPM, MILI e Citrato de Simmons (Merck ${ }^{\circledR}$ ) (NASCIMENTO et al., 2000 modificado).

As análises microbiológicas para pesquisa de Salmonella spp. foram feitas em meio seletivo. $25 \mathrm{~g}$ de salsicha foram homogeneizadas em 225 $\mathrm{mL}$ de água salina peptonada, por 60 segundos e incubada a $36 \pm 11^{\circ} \mathrm{C}$ por $24-48$ horas. Após esse período, $1 \mathrm{~mL}$ foi adicionado em $9 \mathrm{~mL}$ de Tetrationato $($ Oxoid $\AA)$ em banho-maria a $41^{\circ} \mathrm{C}$ por 24-30 horas. Posteriormente, foram cultivadas $0,1 \mathrm{~mL}$ ) em placas de Agar SS (Prodimol $\AA$ ) bubmetidà à submetidas à identicação por provas bioquímicas: kit EPM, MILI e citrato de Simmons (Merck®) (NASCIMENTO et al., 2000 modificado). Todo $o$ procedimento foi realizado em duplicata para confirmação dos resultados.

Após o isolamento de Salmonella spp, foi

realizada a sorologia com soro-polivalentes AntiSalmonella flagelar e somático (PROBAC ${ }^{\circledR}$ ).

\section{RESULTADOS E DISCUSSÃO}

Coliformes são bacilos Gram negativos, não esporulados, capazes de fermentar a glicose com produção de ácido e gás. Os totais compõem dessa habilidade associada à capacidade de fernentar lactose $\mathrm{p}$ também conhecidos como termotolerantes, realizam a fermentação da lactose em temperatura de $44,5^{\circ}$ C no período de 24-48 horas. Esse grupo inclui três gêneros: Escherichia coli, Enterobacter spp Klebsiella spp (BRIGIDO et al, 2004; FRANCO; LANDGRAF, 2004; SILVA et al., 2007).

A presença de coliformes fecais nos alimentos é indicativa de contaminação fecal, ou seja, condições higiênico-sanitárias insatisfatórias. A E. coli é o representante entérico comumente pesquisado. $O$ condições h significam contaminação pós-processamento, limpeza e sanitização deficientes (FRANCO; LANDGRAF, 2004).

A Escherichia coli é um micro-organismo pertencente à família Enterobacteriaceae, constituindo parte da microbiota normal do trato intestinal de humanos e de uma grande variedade de animais. Dentre suas principais características destacam-se: bacilos Gram-negativos, não esporulados, capazes de fermentar glicose com produção de ácido e gás; a maioria também fermenta a lactose (JAY, 2005; KASNOWSKI, 2004), anaeróbicos facultativos, oxidase negativa, geralmente catalase positiva e redutores de nitrato, móveis por flagelos peritríquios ou imóveis (MARTINS, 2006; KASNOWSKI, 2004).

Foram analisadas 16 amostras coletadas nos estabelecimentos de pequeno porte e 16 amostras nos de grande porte, totalizando 32 amostras. Deste total, $23(71,8 \%)$ apresentaram crescimento de algum tipo de enterobactéria (Figura 1).
A Resolução RDC No 12, DE 2 DE JANEIRO DE 2001 (Brasil, 2001) estabelece padrões de até 103 UFC de coliformes a $45{ }^{\circ} \mathrm{C} / \mathrm{g}$ de salsicha. Através da quantificação destas bactérias (Unidades Formadoras de Colônia UFC/g), foram demonstradas que várias amostras estavam fora do padrão higiênico (Tabela 1).

De acordo com a literatura, o desenvolvimento de síndromes gastroentéricas pela maioria dos sorogrupos de Escherichia coli é causada a partir da ingestão de 106 a 1010 células viáveis/g de alimento (MARTINS, 2008). Desta forma, de acordo com os resultados observados neste estudo, pode-se concluir que as amostras analisadas são produtos passíveis de levar ao desenvolvimento de quadros de infecção alimentar, representando um risco à saúde coletiva.

$\mathrm{Na}$ análise de Salmonella spp a legislação busca a presença ou ausência em $25 \mathrm{~g}$ de amostra, esperando-se a ausência em qualquer tipo de produto alimentício. Em contrapartida, diversos estudos têm demonstrado a presença desta bactéria no alimento, tornando-o inviável para consumo.

Em estudos, diversos autores têm detectado a presença de Salmonella spp. em embutidos, reportando uma prevalência de contaminação que varia de 0 a 9,1\% (MATTICK et al., 2002). Marques e colaboradores (2006), em uma pesquisa de linguiças frescais comercializadas no município de Lavras - Minas Gerais, não encontraram a presença do microrganismo em nenhuma das amostras. Já, Silva e colaboradores (2002) realizaram análise em 32 amostras de linguiça mista tipo frescal, comercializadas na cidade de Pelotas - Rio Grande do Sul, e encontraram um total de $17,86 \%$ das amostras contaminadas com Salmonella. Marques e colaboradores (2003), avaliando linguiça frescal Salmonella spp. nas 20 amostras analisadas.

Através dos resultados obtidos nesta pesquisa podemos observar que, embora não tenha ocorrido o crescimento de Salmonella spp, houve o isolamento de Escherichia coli em diversas amostras, o que caracteriza má manipulação e higienização, do alimento e do local de comercialização. A presença desta bactéria torna o alimento inviável para consumo, pois pode provocar toxinfecções.

Ao lado dos micro-organismos envolvidos em processos de deterioração, existem os patogênicos. Além da Salmonella spp e E. coli, a Shigella spp pode causar doenças agudas ou crônicas com maior risco em pacientes imunodebilitados (PABST et al., 2003, SILVA et al., 2002, WINOKUR et al., 2001, ZWEIFEL et al., 2004)

O grupo de supermercados que apresentou maio contaminação foram os supermercados de grande porte, devido ao maior fluxo de pessoas e de vendas, sugerindo possível contaminação na manipulação das salsichas (Figura 3). Como são vendidas a granel e acondicionadas em recipientes que permitam a manipulação direta, a má higienização dos utensilios e mãos dos manipuladores podem contaminar as salsichas.

A maior contaminação se deu nos supermercados de grande porte, que, mesmo sendo pequenas redes, apresentam uma ampla estrutura física e estão sempre com grande fluxo de pessoas, fatores estes, importantes para que a higienização fosse tratada com o máximo de cuidado e fossem seguidas as Boas Práticas de manipulação.

Proença (2001) e Ornellas (2001) apresentam a definição de contaminação como sendo a presença de qualquer substância, objeto ou organismo que seja estranho ao alimento, podendo ser prejudicial para saúde ou não. Essa contaminação pode ocorrer de forma direta, indireta ou acidentalmente por agentes que causem alguma ação indesejável a saúde. Segundo Silva Junior (2007), a contaminação também pode acontecer de forma cruzada, entre o contato de alimentos crus com alimentos cozidos, utensílios não higienizados adequadamente, má higienização das mãos após o processamento de um alimento e início de outro e principalmente após a utilização dos sanitários.

Convém ressaltar a extrema importância da higiene dos funcionários envolvidos na manipulação dos alimentos. Estes não devem possuir lesões e nem serem portadores de doenças 
gastrointestinais, sendo importante que sejam submetidos a treinamentos adequados e a trabalhos de conscientização por profissionais aptos e com conhecimento em higiene e sanidade de alimentos (GERMANO et. al., 2000; RITTER et al., 2001).

Scarcelli e Piatti (2002) advertem para a importância da rastreabilidade dos alimentos em todas as fases de produção, industrialização, transporte, distribuição, armazenamento e comercialização, possibilitando ao consumidor obter uma perfeita correlação entre o produto final e a sua origem, permitindo a aquisição de um produto seguro e saudável.

De acordo com Martins (2006), os embutidos comercializados a granel podem ter a sua durabilidade diminuída em função do tipo de embalagem, e aumentando o risco de contaminação e deterioração, durante as várias fases de distribuição e comercialização.

Ferreira e Sobrinho (2003), ao encontrarem um alto índice de coliformes em suas análises, atribuíram a causa às condições higiênicas insatisfatórias, como, por exemplo: contaminação no manuseio, limpeza e sanitizações deficientes de equipamentos e utensílios e falta de refrigeração do produto. Com o resultado obtido, esses autores advertiram para a necessidade do controle desses pontos que provavelmente acarretaram a contaminação.

A presença de coliformes totais esta relacionada com condições inadequadas de higiene do ambiente de processamento e manipulação, já os coliformes termotolerantes estão relacionados com contaminação fecal e tem sido utilizado como forma de avaliar as condições higiênicas de alimentos e a presença de potenciais patógenos (JAY, 2000)

As temperaturas de armazenagem e durante o transporte devem ser mantidas abaixo $\operatorname{dos} 7^{\circ} \mathrm{C}$, o que vai inibir o desenvolvimento dos micróbios patogênicos, enquanto que o armazenamento a temperaturas de $-1^{\circ} \mathrm{C}+0,5^{\circ} \mathrm{C}$ confere aos produtos refrigerados um tempo de vida útil máximo (GIL 2000).

Mantovani e Martine (2006) dizem que a

resolução da Vigilância Sanitária RDC n²16, de 15 de setembro de 2004, estabelece procedimentos de Boas Práticas para serviços de alimentação a fim de garantir as condições higiênico-sanitárias reparado. Esta resolução aplicalgumas das atividades: manipulação, preparação, fracionamento, armazenamento, distribuição, transporte, exposição à venda e entrega de alimentos preparados ao consumo. Abrange os seguintes itens: alimentos preparados, antisepsia (visando à redução da carga microbiana), contaminantes (químico, físico ou microbiológico), limpeza, manipulação de alimentos (qualquer manuseio ou operação na matéria- prima), o manual de boas práticas de fabricação e os Procedimentos Operacionais Padrão que consistem em Programas Operacionais Padronizados, contendo procedimentos que descrevem de forma objetiva e estabelecem instruções sequenciais para a realização de operações rotineiras e específicas na manipulação de alimentos.

Com os resultados obtidos podemos concluir que os manipuladores nos mercados provavelmente não seguiram as orientações de higiene e de boas práticas de manipulação recomendados pela RDC - 216, causando a contaminação das salsichas vendidas a granel

Recomendam-se ações de educação em saúde, destacando os hábitos de higiene pessoal, a lavagem correta das mãos entre as pessoas que manipulam alimentos, observando cuidados na preparação, manipulação, armazenamento e distribuição de alimentos. As principais estratégias de prevenção devem ser: seleção da matéria-prima, utensílios e equipamento cuidadosamente higienizados; fornecimento de água potável e adequado sistema de tratamento de lixo e esgoto; adoção de boas práticas de fabricação e implantação do sistema APPCC (Análise de Perigos e Pontos Críticos de Controle); afastamento dos portadores assintomáticos da área de produção e metodos de preservação e de transporte adequados.

\section{CONCLUSÃO}

É de suma importância levar em consideração algumas situações como a correta manipulação, a utilização de embalagens apropriadas, o transporte e armazenamento de maneira correta, e principalmente seguir as normas de higiene e sanitização que é regulado pelos órgãos de fiscalização, tudo isso com a finalidade de produzir um produto de qualidade e livre de contaminações que possam tornar os alimentos em potencias riscos para saúde pública.

Conclui-se, portanto, que as salsichas vendidas a granel nos supermercados de um município do Noroeste Paulista, não se encontram aptas para o consumo humano.

\section{REFERÊNCIAS}

BOPP, D.J., SAUDERS, B.D, WARING, A.L ACKELSBERG, J., DUMAS, N., BRAUNHOWLAND, E., DZIEWULSKI, D., WALLACE, B.J., KELLY, M., HALSE, T., MUSSER, K.A., SMITH, P.F., MORSE, D.L., LIMBERGER, R.J. Detection, isolation and molecular subtyping of Escherichia coli O157:H7 and Campylobacte jejuni associated with a large waterborne outbreak Journal of Clinical Microbiology, v. 41, n. 1, p 174-180, 2003

BRASIL, Ministério da Agricultura e do Abastecimento. Instrução Normativa $\mathrm{n}^{\circ} 4$, de 31 de março de 2000. Regulamentos técnicos de identidade e qualidade de carne mecanicamente separada, de mortadela, de linguiça, de salsicha. Diário Oficial [da] República Federativa do Brasil, DF, 05 abr. 2000

BRASIL. Agência Nacional de Vigilância Sanitária (ANVISA). RDC $\mathrm{n}^{\circ} 12$, de 2 de janeiro de 2001. Regulamento Técnico sobre Padrões Microbiológicos para Alimentos. Diário Oficial da União, DF, 2001; 2 jan.
BRASIL. Centro de Vigilância Sanitária Divisão de Doenças e Transmissão Hídrica e Alimentar. In: Manual das Doenças Transmitidas por Alimentos. Brasília - DF, Escherichia coli O157: H7- enterohemorrágica. São Paulo. 2002.

Brasil. Ministério da Agricultura, Pecuária e do Abastecimento. Instrução Normativa $\mathrm{n}^{\circ} 62$, de 26 de agosto de 2003. Oficializa os Métodos Analíticos Oficiais para controle de Produtos de Origem Animal e Agua. Diário Oficial [da] República Federativa do Brasil, Brasília, DF, 18 set. 2003. Seção 1 , p. 14

BRIGIDO, B. M., et al. Queijo minas frescal: avaliação da qualidade e conformidade com a legislação. Rev. Inst. Adolfo Lutz, v.63, n.2, p.177185, 2004

Câmara SAV. Surtos de toxinfecções alimentares no Estado de Mato Grosso do Sul no período de 1998-2001. [Monografia]. Campo Grande (MS): Universidade Federal de Campo Grande; 2002.

DUARTE, A.P. Embutidos defumados. 2005 32f. Trabalho acadêmico apresentado ao curso de Química de Alimentos, Universidade Federal de Pelotas, Pelotas - RS, 2005

FERREIRA, M.G.A.B., SOBRINHO, A .J.C. Bovina Moída e Suína (Pernil) "In Natura" e/ ou Refrigerada, em Supermercados, Frigoríficos e Feiras Livres do Município de São Luís, MA Higiene Alimentar, Mirandópolis - São Paulo, v.17, n. 104/105, p. 87-93, jan/fev. 2003.

FORSYTHE, SJ. Microbiologia da segurança alimentar. Porto Alegre: Artmed, Porto Alegre RS; 2002.

FORTUNA J. L., FRANCO R. M. Uma revisão epidemiológica das principais alterações microbiológicas em produtos cárneos embutidos. 
Revista Higiene Alimentar. Mirandópolis - SP 2005; v.19, n.129, p.35-42

FRANCO, B. D. G. M., LANDGRAF, M. Microbiologia dos alimentos. São Paulo - SP: Atheneu, 2004.

FRANCO, R.M. Escherichia coli: Ocorrência em suínos abatidos na grande Rio e sua viabilidade experimental em linguiça frescal tipo Toscana. $p$. 40, Niteroi-RJ, 2002.

GERMANO, M.I.S.; GERMANO, P.M.L.; KAMEI, C.A.K. et al. Manipuladores de Alimentos: Capacitar? É Preciso. Regulamentar? Será Preciso? Higiene Alimentar. Mirandópolis, São Paulo, v. 14 n. $78 / 79.2000$

GIL,J. I. Manual de inspeção sanitária de carnes. $2^{\mathrm{a}}$ edição. Lisboa, Portugal: Fundação Calouste Gulbenkian, 2000.

ICMSF. Microorganismos de los alimentos. Acribia: Zaragoza, Espanha; 2002.

JAY, J. M. 2000. Modern Food Microbiology. Aspen Publishers Inc. Maryland, EUA. 6th ed., p. 511-525.

JAY, J. M. Microbiologia de Alimentos. 6 ed. Porto Alegre: Artmed, Porto Alegre - RS, 2005 $711 \mathrm{p}$.

KASNOWSKI, M.C. Listeria spp, Escherichia coli: Isolamento, identificação, estudo sorológico e inteira e moída, p. 32 Niteroi-RJ, 2004.

MANTOVANINI, M., MARTINI, R. O. Ministério da Agricultura, Pecuária e Abastecimento Editora Opção, 2006. São Paulo - SP. 68p C. C., NASCIMENTO, A. R., PICCOLI, R. antimicrobiano em corte de carne bovina (alcatra)

MARQUES, S. C., BOARI, C. A., BRCKO,

H. Avaliação higiênico-sanitária de linguiças tipo frescal comercializadas nos municípios de Três corações e Lavras-MG. Ciência e grotecnologia, Lavras - MG, v.30, n.6, p.1120-1123, 2006

MARQUES. C., BROCKO, C.C., JUNQUEIRA A. C., BOARI, C. A., VALLE, R. H. P. Avaliação Higiênico Sanitária de linguiças tipo frescal comercializadas no município de Três Corações MG. Revista Higiene Alimentar, Mirandópolis - SP ,v. 17, n. 104/105, p. 110, jan-fev, 2003.

MARTINS, L. L., Avaliação do perfil bacterológico de salsichas tipo "HOT DOG" tradicional e de frango comercializadas nos municípios do Rio de Janeiro e Niterói-RJ com determinação de atividade de água e pH, p. 26 Niteroi-RJ, 2006

MARTINS, L. L., SANTOS, I. F., FRANCO, R. M., OLIVEIRA, L. A. T., BEZZ, J. Avaliação do perfil bacteriológico de salsichas tipo "hot dog" comercializadas em embalagens a vácuo e a granel em supermercados dos municípios Rio de Janeiro e Niterói, RJ/Brasil. Departamento de Tecnologia de Alimentos, Faculdade de Veterinária da Universidade Federal Fluminense/UFF, Rio de Janeiro,RJ/Brasil. Rev. Inst. Adolfo Lutz, São Paulo - SP, 67(3):215-220, 2008.

MATTICK KL, BAILEY RA, JORHENSEN F, HUMPHREY TJ. The prevalence and number of Salmonella in sausage and their destruction by frying, grilling or barbecuing. Journal of Applied Microbiology, Malden - EUA, 2002; 93:541-7.

McCORMICK KE, HAN IY, ACTON IC, SHELDON BW, DAWSON PL. Inpackage pasteurization combined with biocideimpregnated films to inhibit Listeria monocytogenes and Salmonella typhimurium in Turkey Bologna. Journal of Food Science, Ancara,
NASCIMENTO, M.S.; BERCHIERI, Jr. A.; BARBOSA, M.D; ZANCAN, FT. ALMEIDA ORNELLAS, L. H. Técnica Dietética: seleção e preparo dos alimentos. $7^{\mathrm{a}}$ ed. São Paulo - SP: Atheneu, 2001

PABST, W.L., ALTWERGG, K., KIND, D., MIRJANIC, S., HARDEGGER, D., NADAL, D. Prevalence of Enteroaggregative Escherichia coli among children with and without diarrhea in Switzerland. Journal of Clinical Microbiology, v. 41, n. 6, p. 2289-2293, 2003.

PAVIA, P. C., BORGES, R. G., PANETTA, J. C. Frequência de quadros gastroentéricos em aeronautas: pressuposta ligação com toxinfecções alimentares. Revista Higiene Alimentar, Mirandópolis - SP v. 14, n. 75, p. 13 - 23, ago., 2000.

PROENÇA, R. P. C. Desafios Atuais na Alimentação Humana. Departamento de Nutrição. Universidade Federal de Santa Catarina. Revista Nexus, Mapleton, Austrália, 2001.

RITTER, R, SANTOS, D., BERGMANN, G.P. Contaminação Bacteriana da Carne Moída Bovina Comercializada em Bancas do Mercado Público de Porto Alegre, RS. Higiene Alimentar, Mirandópolis,, v.15, n. 85, p. 50- 56, jun. 2001.

SAMUEL CM, VUGIA DJ, KOEHLER KM, MARCUS R, DENNEN V, DAMASKE B, SHIFERAW B, HADLER J, HENAO OL, Angulo FJ. Consumption of risky foods among adults at high risk for severe foodborne diseases: room for improved targeted prevention messages. Journal of Food Safety, Hoboken, New Jersey USA, 2007; 27:219-232.

SCARCELLI, E.; PIATTI, R.M. Patógenos Emergentes Relacionados à Contaminação de Alimentos de Origem Animal. Biológico, São Paulo - SP, v.64, n.2, p.123-127, jul/dez. 2002.
SILVA JUNIOR, E. A. Manual de controle higiênico-sanitário em alimentos. 6. ed. São Paulo - SP: Varela, 2007.

SILVA, N., et al. Manual de métodos de análises microbiológicas de alimentos. $3^{\mathrm{a}}$ ed. São Paulo: Livraria Varela, 2007.

SILVA, W. P, GANDRA, E. A., DUVAL, E. H., JANTZEN, M. M., TESSMANN, C., LIMA, A.S. Qualidade microbiológica de linguiças mistas do tipo frescal produzidas na cidade de Pelotas (RS). Boletim CEPPA, Curitiba - PR, v.20, n.2, p.257266, 2002

W.A.F. Comparação de meios de enriquecimento e plaqueamento utilizados na pesquisa de Salmonella em carcaças e frangos e fezes de aves. Revista Brasileira de Ciência Avicola, v.2, n.1, p.58-64, 2000.

WINOKUR, P.L., VONSTEIN, D.L., HOFFMAN, L.J., UHLENHOPP, E.K., DOERM, G.V. Evidence for Transfer of CMY-2 AmpC $\beta$-lactamase Plasmids between Escherichia coli e Slamonella Isolates from Food Animals and Humans. Antimicrobial Agents and Chemotherapy, v. 45, n. 10, p 2716-2722, 2001.

ZWEIFEL, C., ZYCHOWSKA, M.A., STEPHAN, R. Prevalence and characteristics of shiga toxin-producing Escherichia coli, Salmonella spp and Campylobacter spp isolated from slaughtered sheep in Switzerland. International Journal of Food Microbiology, v. 92, p. 45-53, 2004. 